\title{
Pulse Width Modulation of Three Phase Inverters Based on Linear Programming
}

\author{
Tomáš Komrska ${ }^{1)}$ and Tomáš Glasberger ${ }^{2)}$ \\ 1) RICE, University of West Bohemia in Pilsen, Czech Republic, e-mail: komrska@rice.zcu.cz \\ ${ }^{2)}$ RICE, University of West Bohemia in Pilsen, Czech Republic, e-mail: tglasber@ rice.zcu.cz
}

\begin{abstract}
Traditional three-phase voltage-source inverters supplied by constant dc-link voltage usually utilize the space vector PWM to achieve maximum output voltage. This paper deals with optimization of inverter leg voltages using linear programming method. System definition is based on the relationship between the known voltage vector, which is demanded by an upper control loop and the unknown leg voltages which enter the carrier-based PWM block as modulation signals. A slack variable is introduced to the system as minimization objective, defining border for all leg voltages. Optimization procedure minimizes leg voltage maxima, and thus, the maximum utilization of the dc-link voltage is ensured. The theoretical assumptions have been verified by simulations as well as by experiments on laboratory prototype.
\end{abstract}

Keywords - three-phase inverters, pulse width modulation, linear programming.

\section{INTRODUCTION}

Although multiphase and multilevel systems are becoming more widespread and gaining importance, traditional three-phase three-level voltage-source inverters (VSI) still outnumber others in applications.

Since in most cases, the dc-link voltage is a constant value, limited by supply voltage source and power switch dimensioning, the main target of an employed control technique is to maximize the output voltage at a given $\mathrm{dc}$ level. In other words, it is desirable to minimize the dc-link voltage when generating the output voltage vector demanded by an upper (superior) control loop.

Sinusoidal PWM is likely the most straightforward way to generate a demanded output voltage. However, in this case, the magnitude of achievable voltage vector corresponds to $V_{\mathrm{dd}} / 2$; it is not the maximum which can be reached by the VSI. Therefore, the sinusoidal PWM is often replaced by more advanced approaches.

In applications with delta-connected load or in those, where the centre of star-connected load is insulated, it is possible to increase the output voltage using zero-sequence component which introduces a degree of freedom to the system. The zero-sequence component is exploited by traditional space-vector PWM method (SVPWM) [1-4] and by many carrier-based PWM methods [3, 5-9]. These techniques have been an intense research topic for several decades.

Fig. 1. shows a conventional three-phase voltage-source inverter with the dc-link split to two $V_{\mathrm{dc}} / 2$ sources.

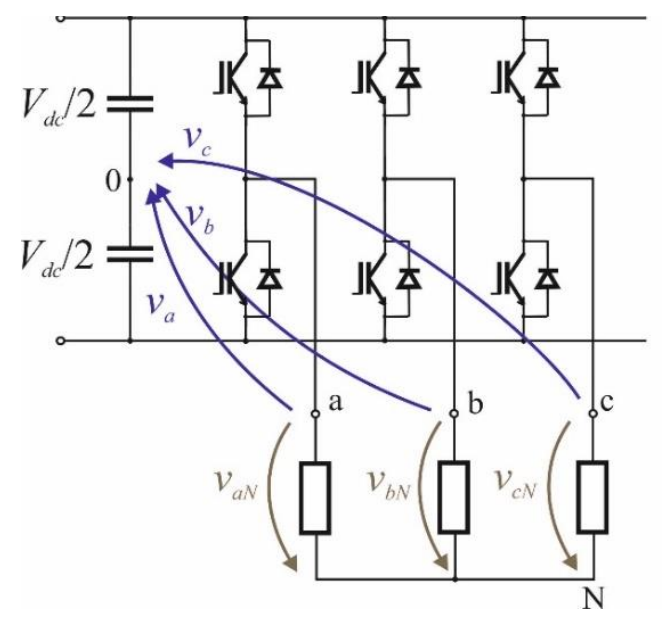

Fig. 1. Three-phase voltage-source inverter.

The leg voltages $v_{a}, v_{b}, v_{c}$ are defined from the ac outputs the dc link middle " 0 ", whereas the load voltages $v_{a N}, v_{b N}, v_{c N}$ can be measured between the ac outputs and the center of a star-connected load.

\section{SVPWM FOR THREE-PHASE CONVERTERS}

The space vector PWM for three-phase converters is widely used and its application is almost straightforward. The active outputs vectors of the converter can be expressed by for each switching combination:

$$
\mathbf{V}=\frac{2}{3}\left(v_{a}+\mathbf{a} v_{b}+\mathbf{a}^{2} v_{c}\right)
$$

where $\mathbf{V}$ is the output vector in a complex plane, $v_{a}, v_{b}, v_{c}$ are instantaneous values of phase voltages which depends on the switching combination in given phases, $\mathbf{a}=e^{j \frac{2}{3} \pi}$ is the complex transformation constant. The output vectors $\mathbf{V}_{0}-\mathbf{V}_{7}$ create a hexagon shown in Fig. 2. The maximum voltage, which will be important for further comparison, obtainable using the SVPWM in the three-phase converter corresponds with the inscribed circle with radius of $V_{d c} / \sqrt{3}$. Arbitrary output vector $\boldsymbol{V}_{\alpha \beta}$ can be created as a switching combination of two neighboring vectors in complex plane $\alpha \beta$ and zero vectors (V0, V7), respectively. 


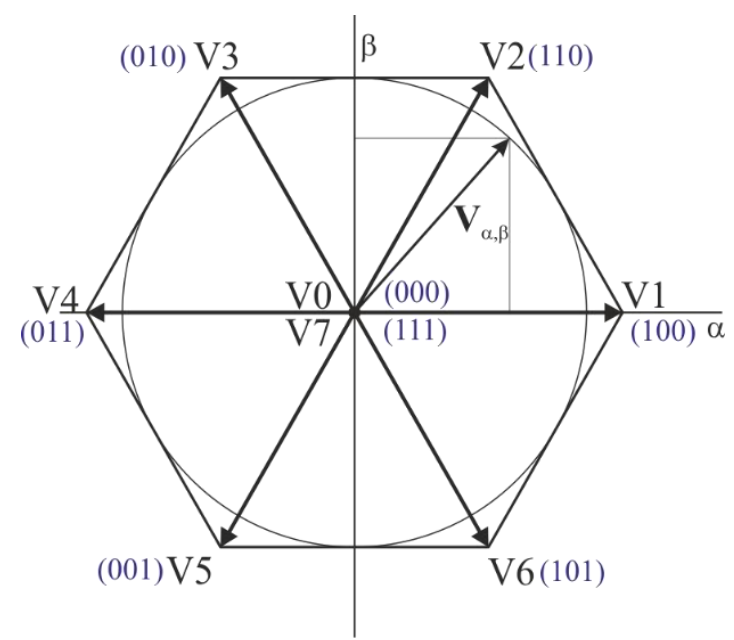

Fig. 2. Basic space vectors for three-phase converters.

\section{TRIANGULAR SignAl InJECTION PWM}

Among the carrier-based methods, triangular signal injection PWM (TIPWM) employs the zero-sequence component and obtained waveforms correspond to those reconstructed from the SVPWM. It is often employed its simplified version when $3^{\text {rd }}$ harmonic voltage is injected as the zero-sequence component:

$$
\begin{aligned}
& v_{a}=1 \sin (\omega t)+\frac{1}{6} \sin (3 \omega t), \\
& v_{b}=1 \sin \left(\omega t-\frac{2}{3} \pi\right)+\frac{1}{6} \sin (3(\omega t- \\
& \left.\left.\frac{2}{3} \pi\right)\right), \\
& v_{c}=1 \sin \left(\omega t+\frac{2}{3} \pi\right)+\frac{1}{6} \sin (3(\omega t+ \\
& \left.\left.\frac{2}{3} \pi\right)\right),
\end{aligned}
$$

The waveforms are depicted in Fig. 3.

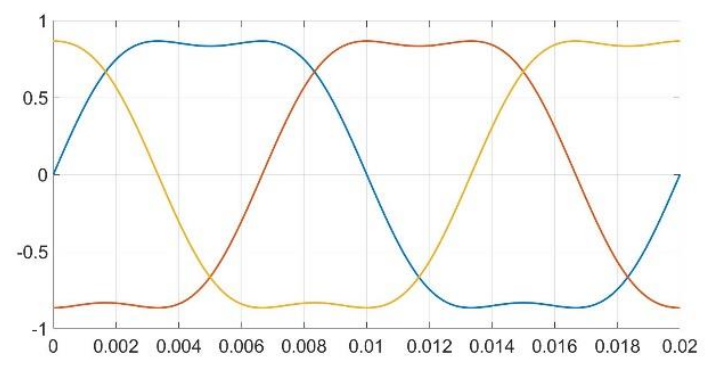

Fig. 3. PWM with $3^{\text {rd }}$ harmonic injection.

It is possible to add other harmonics building the zerosequence component, such as $9^{\text {th }}$ harmonic, etc. Resulting waveform corresponds to the triangular signal and it can be easily obtained as average of maximum and minimum of sinusoidal modulation signals:

$$
v_{a}=M \frac{V d c}{2} \sin (\omega t)
$$

$$
\begin{aligned}
& v_{b}=M \frac{V d c}{2} \sin \left(\omega t-\frac{2}{3} \pi\right), \\
& v_{c}=M \frac{V d c}{2} \sin \left(\omega t+\frac{2}{3} \pi\right), \\
& v_{0}=\frac{1}{2}\left[\max \left(v_{a}, v_{b}, v_{c}\right)+\min \left(v_{a}, v_{b}, v_{c}\right)\right] .
\end{aligned}
$$

The waveform of the desired leg voltage, which can be simply normalized to $V_{\mathrm{dc}} / 2$ and used as a modulation signal, can be obtained by

$$
\begin{aligned}
& m_{a}=\left(v_{a}-v_{0}\right) \frac{2}{V_{d c}}, \\
& m_{b}=\left(v_{b}-v_{0}\right) \frac{2}{V_{d c}}, \\
& m_{c}=\left(v_{c}-v_{0}\right) \frac{2}{V_{d c}} .
\end{aligned}
$$

Resulting waveforms are depicted in Fig. 3.

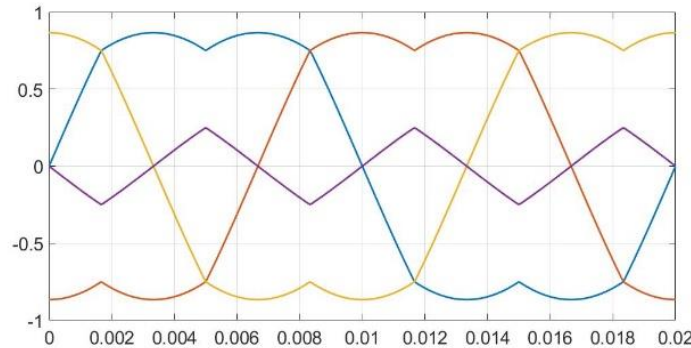

Fig. 4. Triangular signal injection PWM (TIPWM).

\section{LINEAR PROGRAMMING}

Linear programming is a well-known class of optimization problems, in which the objective and all constraint functions are linear [10]:

minimize $f^{T} x$

subject to $a_{i}^{T} x \leq b_{i}, i=1, \ldots, m$.

Here the vectors $f, a_{1}, \ldots, a_{m} \in R^{n}$ and scalars $b_{1}, \ldots, b_{m} \in R$ are problem parameters that specify the objective and constraint functions.

In a standard form, the linear programming includes both, equality and inequality constraints:

$$
\begin{array}{ll}
\text { minimize } & f^{T} x, \\
\text { subject to } & A x=b, \\
& C x \leq d .
\end{array}
$$

In the case of three-phase VSIs, an output voltage vector is demanded $\mathrm{V}_{\alpha \beta}^{*}$ by an upper control loop. As depicted in Fig. 2, its desired trajectory is usually a circle. Actual position of the vector is given by two components $V_{\alpha}, V_{\beta}$, which are determined by three leg voltages $v_{a}, v_{b}, v_{c}$ : 


$$
\left[\begin{array}{l}
V_{\alpha} \\
V_{\beta}
\end{array}\right]=\frac{2}{3}\left[\begin{array}{rrr}
1 & -\frac{1}{2} & -\frac{1}{2} \\
0 & \frac{\sqrt{3}}{2} & -\frac{\sqrt{3}}{2}
\end{array}\right]\left[\begin{array}{l}
v_{a} \\
v_{b} \\
v_{c}
\end{array}\right]
$$

Thus, the system disposes by one degree of freedom (zero-sequence component), and the leg voltage actual values can be objective for optimization.

From this point of view, the desired voltage vector components $V_{\alpha}^{*}, V_{\beta}^{*}$ are known variables and they build the vector $b$ in the equality constraint $A x=b$ in (5). The matrix $A$ is given by the Clarke's transform (6) and the unknown vector $\mathrm{x}$ contains searched leg voltages:

$$
\begin{aligned}
& A=\frac{2}{3}\left[\begin{array}{ccc}
1 & -\frac{1}{2} & -\frac{1}{2} \\
0 & \frac{\sqrt{3}}{2} & -\frac{\sqrt{3}}{2}
\end{array}\right], \\
& x=\left[\begin{array}{lll}
v_{a} & v_{b} & v_{c}
\end{array}\right]^{T} .
\end{aligned}
$$

From the minimum effort control point of view, it is necessary to minimize the leg voltage maxima, needed for generating of the desired output voltage vector.

To do so, we introduce a slack variable $v_{s}$, which is fourth component of the unknown vector $\mathrm{x}$ :

$$
x=\left[\begin{array}{llll}
v_{a} & v_{b} & v_{c} & v_{s}
\end{array}\right]^{T} .
$$

This slack variable will be minimization objective and, contemporary, it builds the inequality constraints as maximum absolute value for the other unknown variables (leg voltages $v_{a}, v_{b}, v_{c}$ ):

$$
\begin{aligned}
& \left|v_{a}\right| \leq v_{s}, \\
& \left|v_{b}\right| \leq v_{s}, \\
& \left|v_{c}\right| \leq v_{s},
\end{aligned}
$$

i.e.

$$
\begin{aligned}
& v_{a}-v_{s} \leq 0,-v_{a}-v_{s} \leq 0 \\
& v_{b}-v_{s} \leq 0,-v_{b}-v_{s} \leq 0 \\
& v_{c}-v_{s} \leq 0,-v_{c}-v_{s} \leq 0
\end{aligned}
$$

These inequality constraints can be rewritten to the matrix form $C x \leq d$ as follows:

$$
\begin{aligned}
C & =\left[\begin{array}{cccc}
1 & 0 & 0 & -1 \\
0 & 1 & 0 & -1 \\
0 & 0 & 1 & -1 \\
-1 & 0 & 0 & -1 \\
0 & -1 & 0 & -1 \\
0 & 0 & -1 & -1
\end{array}\right], \\
d & =\left[\begin{array}{llllll}
0 & 0 & 0 & 0 & 0 & 0
\end{array}\right]^{T} .
\end{aligned}
$$

In order to minimize the slack variable $v_{s}$ only, the vector $f$ of the minimization objective $f^{T} x$ is

$$
f=\left[\begin{array}{llll}
0 & 0 & 0 & 1
\end{array}\right]^{T} .
$$

Thus, the minimization procedure will be applied to the maximum of absolute values of the leg voltages $v_{a}, v_{b}, v_{c}$.

\section{SOLUTION SEARCH}

Unfortunately, there is no simple formula for a solution of a linear programming problem. A usual way to solve the linear convex optimization problems, including the linear programming, is by using of the interior-point methods [10] or the Dantzig's simplex method [11]. The solution has to be found in the feasible region - inside of a complex polytope (Fig. 5), specified by the constraints (5). Whereas the simplex method travels along the constraints (vertices), the interior-point methods go through the inside of the feasible space. However, all these methods are based on iterative algorithms converging to a solution, and therefore, they are not very suitable for an implementation in a realtime environment.

On the other hand, in case of mathematical modelling and simulation results, a PWM block based on linear programming problem can be easily implemented using a library function (e.g. $\operatorname{linprog}()$ in Matlab environment).

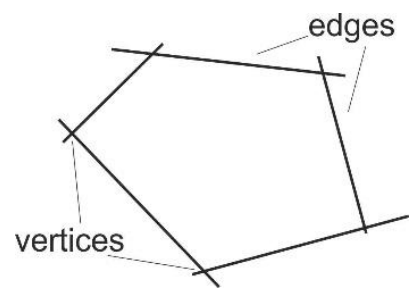

Fig. 5. Convex polytope specifying the feasible region.

\section{SIMULATION RESULTS}

In order to obtain waveforms of optimized leg voltages, it is necessary to perform the minimization procedure discussed above every sampling period. Then, the actualized voltage values can be normalized to $V_{\mathrm{dc}} / 2$ and employed as modulation signals in a standard carrier-based PWM block, as illustrated in Fig. 6.

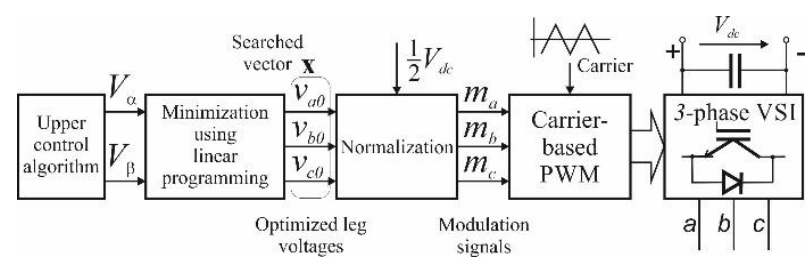

Fig. 6. Block diagram of carrier-based PWM based on linear programming.

Desired voltage vector components $V_{\alpha}^{*}, V_{\beta}^{*}$ come from the superior control algorithm and enter the linear programming block. For the simulation results, the trajectory of the desired vector is a circle with angular frequency of $314.15 \mathrm{rad} . \mathrm{s}^{-1}(50 \mathrm{~Hz})$ and magnitude $\left|V_{\alpha \beta}\right|=$ $69.28 \mathrm{~V}$. Such a vector is achievable with the dc-link voltage of $120 \mathrm{~V}$.

A mathematical model of the whole system has been built in Matlab Simulink/PLECS environment and the Matlab function $\operatorname{linprog}()$ has been adopted for the leg voltage optimization procedure. Resulting waveforms are depicted in Fig. 7, the corresponding spectral analysis is shown in Fig. 8. 


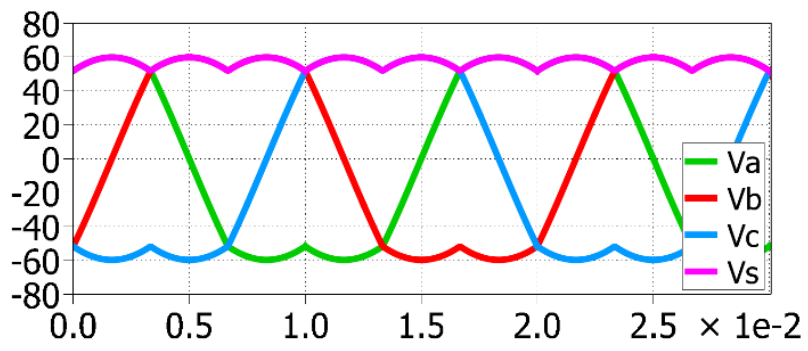

Fig. 7. Leg voltage waveforms $\left(v_{a}, v_{b}, v_{c}\right)$ optimized by linear programming using slack variable $v_{s}$ (magenta).

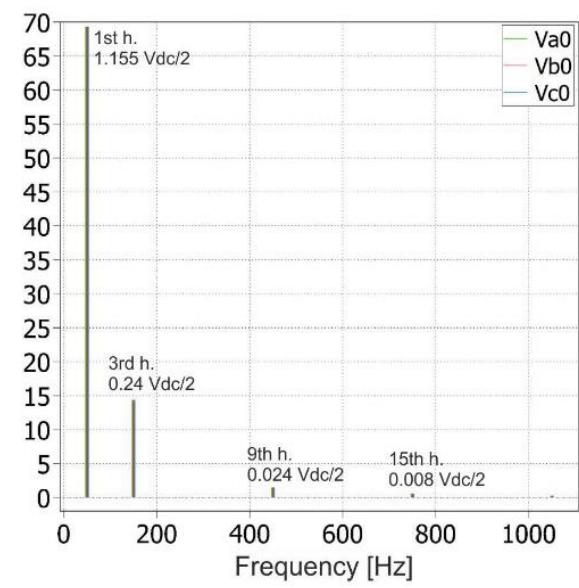

Fig. 8. Spectral analysis of leg voltage waveforms $\left(v_{a}, v_{b}, v_{c}\right)$ optimized by linear programming.

The obtained waveforms $\left(v_{a}, v_{b}, v_{c}\right)$ correspond to the modulation signals generated by the TIPWM or signals reconstructed from the SVPWM. From this it can be concluded that the proposed method utilizes the zerosequence component to minimize the leg voltage maxima and, contemporary, it maximizes the $1^{\text {st }}$ harmonic component. This conclusion is verified by the spectral analysis (see Fig. 8), where zero-sequence harmonic components are present $\left(3^{\text {rd }}, 9^{\text {th }}, 15^{\text {th }}\right.$, etc. $)$.

Fig. 7 illustrates the waveform of the slack variable $v_{s}$ (magenta), used as the minimization objective (5). It corresponds to the maximum absolute value of all leg voltages and, in the same time, it defines a minimum dclink value $\left(V_{d c}\right)$ needed to generate the actual voltage vector demanded by an upper control loop. In this case, the maximum does not exceed the value of $60 \mathrm{~V}\left(V_{\mathrm{dc}} / 2\right)$, so the output voltage is achievable with the dc-link voltage of $120 \mathrm{~V}$.

\section{EXPERIMENTAL RESULTS}

As mentioned above, minimization of the slack variable $v_{s}$ leads to minimization of actual leg voltage maxima. Since the maximum absolute value of all vector components corresponds to the infinity norm defined as

$$
\|x\|_{\infty}=\max \left(\left|x_{1}\right|,\left|x_{2}\right|, \cdots\left|x_{n}\right|\right),
$$

the minimization using linear programming can be redefined as minimum infinity norm optimization problem:

$$
\text { minimize }\|x\|_{\infty},
$$

subject to $y=A x$

where $\mathrm{A}$ is the system matrix (7) and $\mathrm{y}$ is the known vector containing the demanding voltage components $V_{\alpha}^{*}, V_{\beta}^{*}$. The solution can be computed in real time using the Cadzow algorithm, as discussed in [12].

A laboratory prototype of the three-phase voltage-source inverter has been built to perform experimental measurements. The dc-link voltage has been set to $120 \mathrm{~V}$. The rotating voltage vector $V_{\alpha \beta}=\left|V_{\alpha \beta}\right| e^{j \omega t}$, with amplitude $\left|V_{\alpha \beta}\right|=60 \mathrm{~V}$, and frequency of $50 \mathrm{~Hz}(\omega=314,15$ rad. $\left.\mathrm{s}^{-1}\right)$ has been used as the demanded output vector coming from the upper control loop. Obtained experimental results (optimized leg voltage waveforms and demanded component $V_{\alpha}^{*}$ ) are shown in Fig. 9.

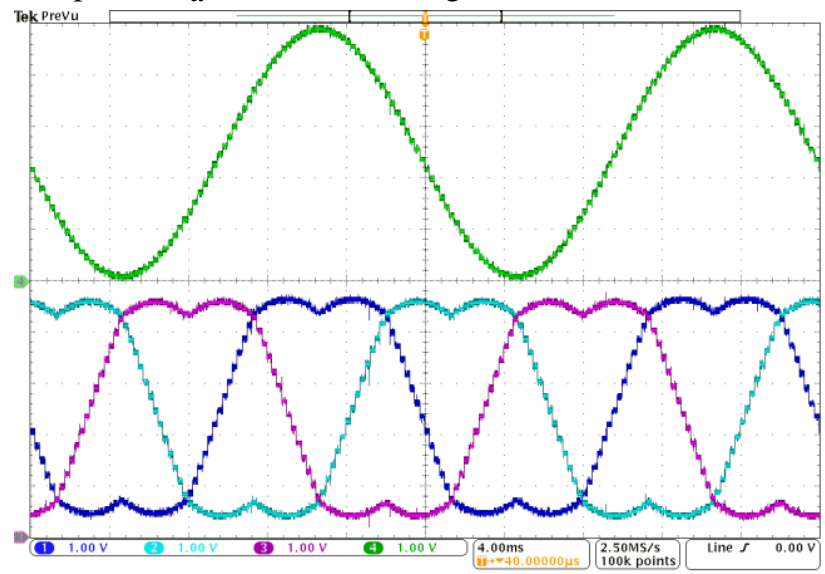

Fig. 9. Experimental results for demanded voltage vector $V_{\alpha \beta}=$ $\left|V_{\alpha \beta}\right| e^{j \omega t},\left|V_{\alpha \beta}\right|=60 \mathrm{~V}, \omega=314.15{\mathrm{rad} . \mathrm{s}^{-1}}:$ Ch1,2,3 Optimized leg voltages [25V/div.]; Ch4 $\mathrm{V}_{\alpha}$ component of the demanded voltage vector $\mathbf{V}_{\alpha \beta}[25 \mathrm{~V} /$ div.].

\section{CONCLUSION}

A carrier-based PWM for conventional three-phase VSI has been defined as a linear convex problem. The optimization procedure based on linear programming is applied in every sampling period. The introduced slack variable, which is the minimization objective, defines a border for values of leg voltages. Hence, the maxima of leg voltage values are minimized and the resulting waveforms are employed as modulation signals in the conventional carrier-based PWM. Such an optimization ensures the maximal utilization of the dc-link voltage. In the same time, the waveforms generated by the linear programming method correspond to those reconstructed from the traditional SVPWM. That means, that both techniques utilize the zero-sequence component to achieve maximum output voltage at a given dc voltage level.

\section{ACKNOWLEDGMENT}

This research has been supported by the Ministry of Education, Youth and Sports of the Czech Republic under project No. SGS-2018-009. 


\section{REFERENCES}

[1] S. K. Mondal, B. K. Bose, V. Oleschuk, and J. O. P. Pinto, "Space vector pulse width modulation of three-level inverter extending operation into overmodulation region," IEEE Transactions on Power Electronics, vol. 18, no. 2, pp. 604-611, 2003.

https://doi.org/10.1109/TPEL.2003.809342

[2] Y. Jiaxin, P. Jianbing, F. Wenli, C. Chao, C. Yaojun, and C. Baichao, "An Immune-Algorithm-Based Space-Vector PWM Control Strategy in a Three-Phase Inverter," Industrial Electronics, IEEE Transactions on, vol. 60, no. 5, pp. 2084-2093, 2013. https://doi.org/10.1109/TIE.2012.2227899

[3] J. Holtz, "Pulsewidth modulation-a survey," IEEE Transactions on Industrial Electronics, vol. 39, no. 5, pp. 410-420, 1992. https://doi.org/10.1109/41.161472

[4] H. W. v. d. Broeck, H. Skudelny, and G. V. Stanke, "Analysis and realization of a pulsewidth modulator based on voltage space vectors," IEEE Transactions on Industry Applications, vol. 24, no. 1, pp. 142-150, 1988. https://doi.org/10.1109/28.87265

[5] J. C. Salmon, "A critical survey of techniques used in 3-phase carrierbased PWM to lower the current distortion," Fifth Annual Proceedings on Applied Power Electronics Conference and Exposition, pp. 253-261, 1990.

https://doi.org/10.1109/APEC.1990.66418

[6] A. M. Hava, R. J. Kerkman, and T. A. Lipo, "Simple analytical and graphical methods for carrier-based PWM-VSI drives," Power Electronics, IEEE Transactions on, vol. 14, no. 1, pp. 49-61, 1999. https://doi.org/10.1109/63.737592
[7] S. Nonaka, "A novel three-phase sinusoidal PWM voltage source inverter and its application for photovoltaic power generation system," Power Conversion Conference - Nagaoka 1997., Proceedings of the, vol. 2, pp. 755-758 vol.2, 1997. https://doi.org/10.1109/PCCON.1997.638308

[8] Z. Min, D. Atkinson, and M. Armstrong, "A zero-sequence component injected PWM method with reduced switching losses and suppressed common-mode voltage for a three-phase four-leg voltage source inverter," IECON 2012 - 38th Annual Conference on IEEE Industrial Electronics Society, pp. 5068-5073, 2012. https://doi.org/10.1109/IECON.2012.6389561

[9] K. Jang-Hwan and S. Seung-Ki, "A carrier-based PWM method for three-phase four-leg voltage source converters," Power Electronics, IEEE Transactions on, vol. 19, no. 1, pp. 66-75, 2004. https://doi.org/10.1109/TPEL.2003.820559

[10][S. Boyd and L. Vandenberghe, Convex Optimization. Cambridge: Cambridge University Press, 2004.

[11] G. B. Dantzig, Linear programming and extensions. Princeton Univ. Press, Aug. 1998.

[12] T. Komrska, T. Glasberger, and Z. Peroutka, "Minimum Infinity Norm-Based PWM for Three-Phase Four-Leg Converters," 2019 IEEE 28th International Symposium on Industrial Electronics (ISIE), pp. 902-907, 2019.

https:/doi.org/10.1109/ISIE.2019.8781324 